\title{
¿Una Inmaculada de Luis Salvador Carmona en Estepa?
}

\author{
Jorge Alberto Jordán Fernández \\ Doctor en Historia
}

\section{LA OBRA DE LUIS SALVADOR CARMONA EN ESTEPA}

Fue el franciscano fray Martín Recio, de quien hemos tomado prestado el título para este artículo, ${ }^{1}$ el primero que dio a conocer, en 1974, la presencia en Estepa de una obra del escultor vallisoletano Luis Salvador Carmona (Nava del Rey, 1708 - Madrid, 1767), ${ }^{2}$ atribución que con toda cautela, y también humildad franciscana de que el religioso hizo gala toda su vida, establecía, en base a ciertas pruebas documentales y al notable parecido de la imagen estepeña con otra del mismo Salvador Carmona conservada en el Museo de León, ${ }^{3}$ la más que posible autoría del mencionado escultor para una imagen de San Francisco de Asís que se venera hoy en la iglesia del convento que los franciscanos tienen en esta ciudad andaluza; descubrió el P. Martín en los libros de cuentas del V.O.T. de San Francisco de Estepa una serie de pagos realizados entre 1743 y 1746 relacionados con la hechura de un San Francisco, precisamente durante los años en que fue hermano ministro de dicha orden tercera don Juan Bautista Centurión (Madrid, 1718 - 1785), VII marqués de Estepa (1733-1785), quien, teniendo casa en Madrid, donde residió habitualmente, es probable que estuviera en contacto con los artistas de la época, y el mejor entre ellos en la capital de España era Salvador Carmona, y, como es natural, le encargaría la imagen de San Francisco. ${ }^{4}$

1 P. Martín RECIO, “Un San Francisco de Salvador Carmona en Estepa?”, en Archivo Español de Arte, tomo $47, n^{\circ} 187,1974$, pp. 330-331.

2 Sobre la vida y obra de este escultor existen dos monografías muy bien documentadas: Juan José MARTÍN GONZÁLEZ, Luis Salvador Carmona. Escultor y académico, Madrid, 1990, y Ma Concepción GARCÍA GAÍNZA, El escultor Luis Salvador Carmona, Pamplona, 1990; aunque coincidimos con Jesús Urrea en que va siendo hora de pensar en una nueva y más completa monografía... (en la presentación de Luis Salvador Carmona (1708-1767). Nava del Rey. Convento de MM. Capuchinas, mayo-junio 2009, Valladolid, 2009, p. 7).

3 RECIO, ob. cit., p. 331.

4 Ibídem. 
Esta atribución, sin embargo, fue acogida al principio con reservas por los estudiosos del arte, ${ }^{5}$ y no sería hasta el año 1990 que los especialistas confirmaron plenamente la misma. ${ }^{6}$ A partir de entonces la nómina de esculturas atribuidas a Salvador Carmona existentes en Estepa comenzó a aumentar progresivamente; así, el propio Martín González, en 1990, incluyó entre ellas la escultura de San Juan Bautista, fechable hacia 1747, que se halla hoy en el retablo de la cabecera de la nave del evangelio de la iglesia estepeña de San Sebastián, procedente de la desaparecida ermita de San Juan; ${ }^{7}$ en 1996 el profesor Gómez Piñol añadió a este catálogo las imágenes de Jesús Nazareno, realizada en torno a $1759,{ }^{8}$ y San Francisco de Paula, entre 1757-1759, existentes ambas en la parroquia de San Sebastián, si bien a esta última, procedente de la desaparecida iglesia del convento de La Victoria, la consideraba una obra del taller o bien de una fase tardía y debilitada del trabajo del propio artista; ${ }^{9}$ en 1999, el profesor Herrera García atribuía a Salvador Carmona y su taller una escultura de San Joaquín con la Virgen Niña en brazos, realizada entre 1740-45 y conservada en el monasterio estepeño de Santa Clara de Jesús, de religiosas clarisas, imagen donada al cenobio por doña $\mathrm{M}^{\mathrm{a}}$ Leonor de Velasco (1698-1745), madre del VII marqués, don Juan Bautista Centurión; ${ }^{10}$ por último, Díaz Fernández, el año 2000, consideró obra indudable de Salvador Carmona una escultura de San José con el Niño en brazos, realizada hacia 1754 y custodiada en la ermita de Ntra. Sra. del Carmen de Estepa. ${ }^{11}$

De manera que puede afirmarse, a la vista de lo que acabamos de exponer, que esta ciudad sevillana posee entre los muros de sus templos y conventos una muestra bastante representativa de la obra del escultor de Nava del Rey y de su taller. Las razones que explican este hecho están todavía pendientes de

5 Así la Guía artística de Sevilla y su provincia en su primera edición (1981) se refería a la imagen de San Francisco diciendo que presenta afinidades con la escuela granadina de finales del siglo XVII aunque también parece relacionable con círculos madrileños de los inicios del siglo XVIII; cfr. VV. AA., Guía artística de Sevilla y su provincia, Sevilla, 1981, p. 650 (en la 2a edición de esta obra, del año 2004, se omite esta cautela y se considera obra de Salvador Carmona; cfr. t. II, p. 463).

6 MARTÍN GONZÁLEZ, ob. cit., pp. 281-285, y GARCÍA GAÍNZA, ob. cit., p. 104.

7 Cfr. MARTÍN GONZÁLEZ, ob. cit., p. 281 y 285.

8 En un inventario de bienes del escultor, fechado en 1759, se dice que el marqués de Estepa le adeudaba 1.000 reales por la hechura de una cabeza y manos para una efigie de Jesús Nazareno que tiene mandados hacer y al presente tiene, dato que a la par que confirma la autoría, establece la cronología aproximada; cfr. Ezequiel DÍAZ FERNÁNDEZ, "La obra del escultor Luis Salvador Carmona en Estepa", en Boletín de Arte, n 23, 2002, p. 264, quien toma el dato de M. C. GARCÍA GAÍNZA y C. CHOCARRO BUJANDA, "Inventario de bienes del escultor Luis Salvador Carmona", en Boletín de la Real Academia de San Fernando, no 86, 1998, p. 229.

9 Emilio GÓMEZ PIÑOL, "La imagen de Jesús Nazareno de Estepa: una propuesta de atribución a Luis Salvador Carmona", en VV. AA., Actas de las II Jornadas sobre Historia de Estepa. El marquesado de Estepa. 7, 8 y 9 de marzo de 1996, Estepa, 1998, pp. 535-557, la cita en p. 557.

10 Cfr. Francisco Javier HERRERA GARCÍA, "Retablos y esculturas que hay en este monasterio de Santa Clara de Jesús", en VV. AA., Clausura. Monasterio de Santa Clara de Jesús de Estepa (1599-1999), Estepa, 1999, pp. 216-219.

11 Ezequiel DÍAZ FERNÁNDEZ, "Un San José de Luis Salvador Carmona en Estepa", en VV. AA., Actas de las V Jornadas sobre Historia de Estepa, Estepa, 2000, pp. 490-500. 
un estudio más riguroso, pero se apunta al conocimiento que debió trabar don Juan Bautista Centurión con el artista de Nava del Rey, bien de primera mano o a través de familiares (se ha dicho antes que la madre del marqués, ya viuda, presumiblemente realizó un encargo al taller de Salvador Carmona), teniéndose en cuenta además que ambos personajes coincidieron en el tiempo residiendo en la corte madrileña: Salvador Carmona, desde el año 1723, adonde llegó como aprendiz, y hasta su muerte en 1767, y Centurión prácticamente toda su vida, si exceptuamos el tiempo que residió en la villa de Estepa, aproximadamente entre los años 1736 y 1744-46, según nos informa el P. Alejandro del Barco;'; se ha querido ver también un posible vínculo entre ellos al hilo de sus relaciones con la Venerable Orden Tercera (V.O.T.) de San Francisco, probada documentalmente en el caso del marqués de Estepa, ya que fue hermano ministro de la estepeña entre 1743-1746, y sólo apuntada en el caso del escultor: consta que su padre fue miembro de esta corporación, se sabe que el artista pidió ser amortajado con el hábito franciscano y también que realizó varios encargos para la orden tercera franciscana en localidades como Estepa, Olite o Yepes. ${ }^{13}$

\section{UNA INMACULADA ESTEPEÑA QUE NO ES DE JUAN DE ASTORGA}

El mismo P. Martín, dos años después de aquel descubrimiento, dio a conocer al gran público la atribución de otra imagen, una Inmaculada Concepción que recibe culto en la ermita de Los Remedios de Estepa, al escultor Juan de Astorga Cubero (Archidona, 1777- Sevilla, 1849); ${ }^{14}$ escribía el franciscano en 1979 lo que sigue: ${ }^{15}$

Se trata de una efigie de la Concepción -imagen de candelero- del siglo XIX. Perteneció a la ermita que llevaba su nombre, que fue erigida por el séptimo marqués de Estepa, don Juan Bautista Centurión. Actualmente se venera en un artístico camarín sobre rico trono [en la iglesia de Los Remedios]. En el catálogo de la iglesia aparecía como de escaso interés artístico. Hasta que se fijó en ella el grupo de chicos de "Misión Rescate» del Colegio Libre Adoptado San Antonio de Padua. Tras un largo estudio, bajo la dirección de un profesor del centro [el P. Recio], ha sido identificada como obra del famoso escultor sevillano Juan de Astorga. El informe presentado por el grupo resume así sus conclusiones:

12 P. Alejandro DEL BARCO, om, La antigua Ostippo y actual Estepa, ms, 1788, edición: Estepa, 1994, pp. 273 y 277.

13 Cfr., para los datos del escultor: DÍAZ FERNÁNDEZ, ob. cit., y P. Alejandro RECIO VEGANZONES, ofm, "Dos imágenes barrocas de San Francisco en Estepa, obras de los escultores Luis Salvador Carmona y Miguel Márquez", en VV. AA., Actas del II Curso de Verano 'El Franciscanismo en Andalucía: san Francisco en la historia y en el arte andaluz, Córdoba, 1998, pp. 235-256, en concreto, p. 239.

14 Sobre la vida y obra de este artista pueden consultarse: José Ignacio RUIZ ALCAÑIZ, El escultor Juan de Astorga, Sevilla, 1986.

$15 \quad$ ABC de Sevilla, 17 de diciembre de 1976, p. 45. 
«Visitando la iglesia, nos fijamos en la finura de la cara de la cara de la Virgen y nos pareció obra de un buen escultor. (...). Nuestra alegría fue grande cuando localizamos en la suela de la sandalia una inscripción que dice 'Astorga me fecit en Sevilla' (Me hizo Astorga en Sevilla)».

Sin embargo esta nueva atribución no gozó de la misma aceptación unánime por parte de la crítica especializada; en 1986, Ruiz Alcañiz, en su monografía sobre Astorga, la incluyó en el catálogo del escultor, pero creemos que con cierta ligereza:

Y finalmente, existen dos imágenes que llevan en sus cuerpos la firma de Astorga, pero sin concretar fecha de realización. Una de estas imágenes se encuentra en la iglesia de Nuestra Señora de los Remedios, en Estepa. Se trata de una talla de candelero, bajo la advocación de la Inmaculada Concepción, y cuya firma fue descubierta en el año 1976, gracias a la labor de investigación llevada a cabo por los alumnos del Instituto «San Antonio de Padua». Esta firma se encuentra en la planta del pie, con la siguiente inscripción: 'Astorga me fecit en Sevilla', similar a las que hemos encontrado en tallas firmadas. La finura de su rostro habla de un buen escultor detrás de ella; y en sus aspectos iconográficos, guarda cierta semejanza en sus rasgos con la imagen de Nuestra Señora de las Nieves, de la iglesia de Santa María la Blanca y con la Magdalena del paso de «Duelo» de la Hermandad sevillana del Santo Entierro.

Y decimos con cierta ligereza porque en el texto que acabamos de trascribir se deslizan algunos errores de bulto; así, el autor dice que la 'firma' se encuentra en la planta del pie, cuando ya hemos visto que se encuentra en la suela de la sandalia; por otro lado, no existe, que sepamos, 'firma' de Astorga, como sostiene el autor, sino solamente la inscripción, y así lo cuenta el P. Martín en el artículo de prensa citado más arriba; parece, pues, que Ruiz Alcañiz no ha visto la imagen y sólo la conoce por el recorte de prensa y alguna foto.

A pesar de lo expuesto, todavía hay algunos estudiosos del arte que mantienen la autoría de Astorga para esta imagen de la Inmaculada, ${ }^{16}$ aunque la tónica general es que sea descartada, como hacen los autores de la Guía artística de Sevilla y provincia, quienes se limitan a decir acerca de esta escultura que es una Inmaculada de vestir del siglo XIX, colocada sobre una peana del siglo anterior. ${ }^{17}$ Creemos que resulta muy significativo, en este mismo sentido, el hecho de que el profesor Roda Peña, que ha dedicado varios trabajos a la figura de Juan de Astorga, no haya hecho mención en ninguno de ellos a esta imagen estepeña de la Inmaculada. ${ }^{18}$

16 Cfr. José FERNÁNDEZ FLORES, Guía histórico-artística de Estepa (Sevilla), Estepa, 1999, p. 80;VV. AA., Cuadernos de la Estepa monumental. Iglesia de Ntra. Sra. de los Remedios, Estepa, 2000, p. 41.

17 VV. AA., Guía..., ob. cit., t. II, p. 456.

18 Cfr. José RODA PEÑA, "Nuevos testimonios biográficos y artísticos sobre el escultor Juan de Astorga", en Laboratorio de Arte, $\mathrm{n}^{\circ}$ 10, 1997, pp. 269-288; ID., "Nuevas noticias sobre Juan de Astorga y las cofradías de Sevilla", en Boletín de las cofradías de Sevilla, n 476, 1998, pp. 47-52; ID., "Juan de Astorga: novedades biográficas y aportaciones a su catálogo escultórico", en VV. AA., Nuevas perspectivas críticas sobre historia de la escultura sevillana, Sevilla, 2007, pp. 142-162; ID, "Juan de Astorga, restaurador", en Laboratorio de Arte, n 23, 2011, pp. 351-374; 
Nos parece evidente que la imagen en cuestión no se ajusta estilísticamente al quehacer de Astorga Cubero, pero por si esto no fuera suficiente, vamos a intentar reconstruir la historia de esta Inmaculada.

Ya sabemos que la imagen de la Virgen procede de la desaparecida ermita de la Concepción, que existió en la calle Ancha, frente a la también desaparecida iglesia del convento de laVictoria; esta ermita fue cerrada al culto por decreto del arzobispado hispalense de 17 de enero de 1928 y, aunque no se tiene constancia documental, es posible que poco tiempo después la imagen de la Inmaculada fuese trasladada a la iglesia de Los Remedios, pues así lo solicitaba el párroco, donVíctor Gamazo, a la autoridad diocesana: en vista de todo ello, creo de necesidad el suspender en absoluto el poquísimo culto que se daba en dicha iglesia, el trasladar la imagen principal de la misma a la iglesia de Ntra. Sra. de los Remedios... ${ }^{19}$

Un inventario de la ermita de la Concepción del año 1909 nos informa de que la imagen de la Virgen estaba colocada en el camarín, sobre un trono de madera dorada y tallada con cuatro Ángeles, deteriorados, vestida con vestido y manto ordinario, tenía dos cabelleras, una para diario y otra para las fiestas y, entre las alhajas de la imagen cita dos medias lunas de plata para la nube de la Virgen..$^{20}$

Aguilar y Cano, en su Memorial (1888), nos aporta interesantes datos sobre la imagen y el templo en que se veneraba; aunque la cita es larga, creemos merece la pena su lectura: ${ }^{21}$

En 1740 se encontraba la ermita [de la Concepción] muy deteriorada, por lo cual y por estimarse pequeña se anhelaba su reedificación. Coincidió con esto la licencia que obtuvo don Juan Bautista, último marqués por la línea recta de los Centuriones, para que se casara con una tía suya, dándole en penitencia que fabricara un templo, y en vista de la necesidad que en éste se sentía acordó el marqués reedificarlo, destinando a ello los orujos y turbios de todos sus molinos y el importe de las limosnas, que no se desdeñó de pedir personalmente por las calles para tan piadoso objeto. Con tales auxilios se concluyó la nueva ermita en menos de veinte y cinco años, y para su dedicación al culto envió la Marquesa, desde Madrid (donde ya se habian establecido), la primorosa imagen que actualmente se venera en altar mayor, constituyéndose la misma Marquesa su camarera, devoción que después practicaron sus sucesoras.

19 Archivo General del Arzobispado de Sevilla (AGAS), Gobierno, asuntos despachados, legajo 05010. Carta-informe de don Víctor al arzobispado fechada en Estepa el 12 de enero de 1928 y, como consecuencia de la misma, decreto del prelado de 17 del mismo mes y año.

20 Archivo de la parroquia de Santa María de Estepa (APSME), carpeta "Inventarios": Inventario de la Iglesia de Nuestra Señora de la Concepción de Estepa. Año de 1909, si bien, el documento finaliza con la fecha de 13 de noviembre de 1911.

21 Antonio AGUILARY CANO, Memorial Ostipense, Estepa, 1886-1888, edición facsímil: Estepa, 2014, t. II, pp. 104-105 (la negrita es nuestra). Sigue muy de cerca Aguilar en este relato lo que cuenta un curioso manuscrito de finales del siglo XVIII y comienzos del siguiente conservado hoy en el convento de San Francisco de Estepa (cfr. Jorge Alberto JORDÁN FERNÁNDEZ, Un manuscrito inédito sobre historia de Estepa y de la recolección franciscana en Andalucía, Estepa, 2005, p. 61). 
Vemos pues cómo Aguilar y Cano identifica la imagen de la Inmaculada que él ve en el altar mayor con la que enviaron los marqueses de Estepa desde Madrid a mediados del siglo XVIII; no puede dudarse de que si el autor del Memorial hubiese tenido noticia de la hechura de una nueva imagen que sustituyera a la que él cita habría dejado constancia de tal hecho, como hizo al mencionar la obra de reparación que en la citada ermita hace pocos años llevó a cabo el señor don José Maximino Téllez, presbítero encargado de este templo. ${ }^{22}$

Una prueba documental avala lo expuesto por Aguilar y Cano; se trata de otro inventario de la misma iglesia, fechado en 1852, que, al mencionar escuetamente la imagen de la Virgen, nos proporciona un dato clave: La imagen de Ntra. Sra., que fue colocada en la ermita que costearon los Señores Marqueses en 4 de octubre de $1756 .{ }^{23}$

Un tercer inventario de los bienes existentes en la ermita de la Concepción, fechado el 20 de marzo de 1791, nos aporta un nuevo detalle acerca de la imagen que nos ocupa, a la que distingue además de otra con la misma advocación que existía en la iglesia y que, al parecer, era más antigua: ${ }^{24}$

La imagen de María Santísima, de vestir, antigua, que no se hace memoria de donde vino, denominada la Real.

Otra imagen de vestir, que enviaron de Madrid los Excmos. Sres. Marqueses de este Estado, con su corona de plata.

Resumiendo, pues, cuanto llevamos dicho podemos concluir que la imagen de vestir de la Inmaculada que hoy recibe culto en la iglesia estepeña de Los Remedios procede de la antigua ermita de la Concepción de la misma ciudad, donde era venerada en un camarín, colocada sobre un trono de madera dorada y tallada con cuatro Ángeles, con cabellera de pelo y una media luna para la nube, y que dicha imagen fue enviada desde Madrid por la esposa y tía de don Juan Bautista Centurión, VII marqués de Estepa, a la mencionada

22 AGUILARY CANO, ob. cit., p. 105. Esta obra se realizó entre los años 1877 y 1878, según anotación inserta en un libro de la parroquia de Santa María de Estepa (APSME, libro de bautismos $\mathrm{n}^{\mathrm{o}} 28, \mathrm{~s} / \mathrm{f}$ ).

23 Archivo del Marquesado de Estepa, legajo 274, caja CXIII: Inventario que yo, don Francisco Muñoz Fernández, presbítero, encargado en el culto y ermita de Ntra. Sra. de la Concepción, doy al Sr. D. Francisco Martínez de Córdoba, administrador del Excmo. Sr. Marqués de Valmediano, Ariza y este Estado, de todas las ropas y alhajas que existen en referida ermita, de la propiedad de dicho Sr. Excmo. Estepa. 15 de abril de 1852. El inventario cita también las dos cabelleras de Ntra. Sra. y los dos brazos de media luna de plata, que se mencionan en el inventario de 1909. Agradecemos públicamente a Moisés Caballero el habernos proporcionado esta referencia documental.

24 Archivo Histórico Nacional (AHN), Consejos, legajo 7008, libro 2 (4). Relación jurada y firmada que yo, D. Juan de Rojas y Navajas, presbitero, teniente primero de la hermandad del Santo Rosario de Ntra. Sra. de la Concepción de esta villa (...) en virtud de orden del Real y Supremo Consejo de Castilla, que a este fin se nos hizo saber, así de las alhajas que existen y sirven de adorno a su iglesia, algunas de ellas dadas de gracia por diferentes devotos y otras hechas a expensas de la hermandad (...). Estepa a veinte de marzo de 1791 (la negrita es nuestra). 
iglesia, que había sido reconstruida a su costa, adonde llegó el 4 de octubre de 1756.

Descartada pues la autoría de la imagen por parte de Juan de Astorga Cubero queda ahora resolver la cuestión de la inscripción que el P. Martín, y su grupo de "Misión Rescate", localizó en la suela de la sandalia del pie derecho de la imagen el año 1979: Astorga me fecit en Sevilla.

Creemos que la solución más probable a esta cuestión pasaría por considerar que la inscripción se refiere solamente a los pies de la imagen y no al conjunto de la misma; pies que bien pudieron realizarse en el trascurso de unos trabajos de restauración en la escultura en una fecha indeterminada del siglo XIX, en cuyo caso sí que se podría admitir que el Astorga de la inscripción fue Juan de Astorga, acerca de cuya labor como restaurador de imágenes también existe constancia, ${ }^{25}$ aunque caben también otras dos posibilidades, pues la saga artística de los Astorga no se terminó con el eximio escultor de Archidona:

Fue continuada por su hijo Gabriel de Astorga Miranda (Sevilla, 18041895), en cuyos trabajos también destaca su faceta de restaurador, ${ }^{26}$ y de quien se conocen algunas noticias, aunque difusas, que lo relacionan con trabajos de restauración en Estepa. ${ }^{27}$

Y también por un hijo adoptivo del anterior, conocido como Gumersindo Jiménez Astorga (Sevilla, 1832-1902), de quien también nos consta que realizó algunos trabajos de restauración en Estepa y alrededores; así, sabemos que en 1883 talló unos nuevos pies y piernas para la imagen de Jesús Nazareno que se venera en la iglesia de San Sebastián de Estepa, a la que ya nos hemos referido más arriba, en sustitución de los primitivos (que no eran de Salvador Carmona): ${ }^{28}$

Lástima que escultura tan bella y completa resulte algo defectuosa en la parte de pies y piernas, pues carcomidas por el tiempo las primitivas, fueron substituidas por las que hoy tiene cuando fue Hermano Mayor el año 1883 D. Andrés Palacios Muñoz, quien pagó por ellas 757 reales al escultor D. Gumersindo Jiménez Astorga y las cuales no guardan analogía con lo restante del cuerpo.

Jiménez Astorga también restauró en 1873 las imágenes escultóricas de Jesús Nazareno y la Virgen de los Dolores de la iglesia parroquial de la vecina localidad

25 Véase especialmente José RODA PEÑA, "Juan de Astorga, restaurador", en Laboratorio de Arte, n 23, 2011, pp. 351-374.

26 Cfr. Daniel PINEDA NOVO, Escultura e imaginería, Sevilla, 1981, p. 76, y RODA PEÑA, "Un Niño Jesús del escultor Gabriel de Astorga", en Laboratorio de Arte, n 4, 1991, pp. 341-346.

27 Cfr. Moisés CABALLERO PÁEZ e Hipólito SANCHIZ ÁLVAREZ DE TOLEDO, "El mecenazgo de los marqueses de Cerverales en las cofradías de Estepa. El manto de Nuestra Señora de la Asunción", en Assumpta, no 1, 2014, pp. 14-15.

28 Antonio GARCÍA ALMANSA, Breves datos históricos y tradicionales de la cofradía de Ntro. Padre Jesús Nazareno, establecida en la parroquia de San Sebastián de esta ciudad, coleccionados por D..., hermano mayor de la misma, Estepa, 1908, p. 30. 
de Gilena: desconocemos en que consistió su intervención en la imagen del Nazareno, no así la de la Dolorosa, a la que agrandó los ojos y la frente y la parte superior de los brazos, trabajos por los que el escultor cobró 600 reales; la imagen restaurada de la Virgen llegó desde Sevilla a la estación de ferrocarril de Aguadulce el 22 de marzo de aquel año. ${ }^{29}$

A cuál de los tres Astorga mencionados cabría adjudicar este trabajo de restauración es algo que no podemos concretar, máxime teniendo en cuenta además que la peana sobre la que apoyan los pies de la imagen, que tampoco es la original, parece haber sido ejecutada por mano distinta de la que hizo dichos pies.

\section{3. ¿PODRÍA LA INMACULADA SER OBRA DE LUIS SALVADOR CARMONA?}

Creemos haber dejado establecido claramente en el apartado anterior el error en que incurrió el P. Martín, y su grupo de "Misión Rescate", al atribuir la hechura de la Inmaculada al escultor Juan de Astorga, si bien, en descargo de estos jóvenes y de su director, hay que decir que para realizar esta atribución contaron con el dictamen favorable de la Escuela de Bellas Artes Santa Isabel de Hungría de Sevilla, cuyo director entonces, Juan Cordero Ruiz, les remitió una misiva el 26 de agosto de 1978 del siguiente tenor: ${ }^{30}$

... consultados los catedráticos de Historia del Arte de este centro, llegan al convencimiento de que la imagen debe ser atribuida a Juan de Astorga por la similitud que se observa entre las fotografías [se refiere a las que le remitió el grupo] en cuestión y las que de este mismo autor se conservan en Sevilla documentadas...

Toca ahora ver qué se puede decir respecto a la adjudicación de la autoría de la imagen de la Inmaculada estepeña a Luis Salvador Carmona o al taller de éste.

Fue precisamente el P. Martín Recio, a nuestro entender, el primero que llamó la atención sobre la posible relación existente entre dicha imagen y el escultor de Nava del Rey, pues terminaba su ya mencionada nota con estas palabras: Por otra parte, sabemos que la señora marquesa doña Luisa Centurión trajo de Madrid a Estepa una bella imagen de la Inmaculada, de vestir, para la capilla, hoy extinguida, de la ermita de la Concepción, de la que eran patronos; ${ }^{31}$ pues no de otro modo pueden ser interpretadas en el contexto en que fueron escritas, como de hecho hizo su hermano, de sangre y de orden religiosa, el P.

29 José REINA y Jesús REINA, Aproximación a la historia de Gilena (siglos XVIII, XIX y XX), Gilena, 2001, pp. 45 y 48.

30 ABC de Sevilla, 17 de diciembre de 1976, p. 45.

31 RECIO, ob. cit., p. 331. 
Alejandro Recio, en un artículo en que glosaba el descubrimiento de su hermano Martín: ${ }^{32}$

Al llegar aquí, permítaseme hipotizar [sic] -siempre dentro del campo de la escultura-que pudiéramos suponer que, tanto la imagen de vestir de la Concepción, como la del Nazareno, hoy en la iglesia de San Sebastián [de Estepa], podrían haber salido del taller madrileño de L. Salvador Carmona.

Y ello es así porque ambos religiosos conocían de primera mano el testimonio que nos dejó en 1788 el religioso mínimo fray Alejandro del Barco, fervoroso defensor de la casa Centurión, acerca de la imagen estepeña de la Inmaculada y su llegada a Estepa: ${ }^{33}$

[Don Juan Bautista Centurión y su esposa y tía] Fueron, asimismo, sumamente aplicados a promover el culto a Dios, la Santísima Virgen y a los Santos, habiéndose dedicado especialmente a fabricarle a la Virgen de la Concepción el magnífico Templo que hoy existe en el mismo sitio de la Ermita antigua, para cuya fábrica, a más de las cuantiosas sumas que sus Excelencias suministraron, no se desdeñaron de salir personalmente por las calles a pedir y recoger las muchas limosnas que ofrecían los fieles; y concluida la Iglesia, hicieron también donación de la singular Imagen que en ella se venera, y mientras vivieron hicieron y costearon siempre la última fiesta de la solemnísima Octava que todos los años se le hace en su respectivo tiempo...

Llegados a este punto, documentalmente ningún testimonio podemos ofrecer más, a pesar de lo cual creemos que queda acreditado que la imagen de que venimos tratando es la misma que los marqueses de Estepa enviaron desde Madrid el año 1756, no así la posible autoría de Salvador Carmona o su taller; sin embargo, cabe preguntarse ¿es posible que los marqueses de Estepa que, como se ha visto, llenaron las iglesias y conventos de la capital de su estado con imágenes del escultor madrileño más sobresaliente del momento, no enviaran ninguna obra de este artista a la iglesia que precisamente se les había mandado reconstruir?

Por lo que se refiere al aspecto artístico, como no somos especialistas en el tema, nada concluyente podemos afirmar y menos tratándose de una imagen de candelero en la que además consta, al menos, una posible intervención restauradora cuyo alcance real desconocemos si se limitó a la parte inferior o incluyó también las manos y el rostro de laVirgen. A pesar de ello, nos atrevemos a decir que apreciamos en ella algunos rasgos estilísticos del quehacer de Carmona o su taller como los siguientes:

- Boca pequeña, de sonrisa apuntada, comisuras de labios rehundidas y un marcado labio superior de contorno lobulado.

32 P. Alejandro RECIO, ob. cit., p. 241.

33 BARCO, om, ob. cit., p. 274. 
- Ojos casi circulares, de abultados y caídos párpados.

- Rostro de perímetro redondeado y marcada barbilla.

- Cejas arqueadas, con un trazo, que se perfila hacia las sienes, de aspecto puntiagudo.

Respecto de la peana y los pies de la imagen poco es lo que podemos decir además de lo ya apuntado: ambos elementos parece que fueron realizados por mano distinta pues no existe armonía en el ensamblaje entre ambas piezas; la peana desde luego no parece obra de Salvador Carmona ni de su taller, incluso puede que se realizase posteriormente, a finales del siglo XVIII o principios del siguiente, pero todo ello no son más que conjeturas sin una base sólida que tal vez estudios más profundos puedan ayudar a confirmar o desechar.

\section{CONCLUSIÓN}

Hemos intentado responder en las páginas anteriores al interrogante que encabeza nuestro artículo y pensamos haber aportado los suficientes elementos de juicio para poder afirmar que es muy posible que la hechura de la imagen de la Inmaculada que se venera hoy en la ermita de Nuestra Señora de los Remedios de la ciudad de Estepa se pueda atribuir al escultor Luis Salvador Carmona o su taller.

Otros, con bastantes menos elementos que nosotros, iniciaron hace ya muchos años el camino por el que ahora hemos transitado y consiguieron que su labor fuera reconocida por los especialistas; ojalá nos quepa a nosotros la misma suerte con el trabajo que hacemos público. 